\title{
The heat transfer characteristics of a mesoscale continuous oscillatory flow crystalliser with smooth periodic constrictions
}

\author{
I. I.Onyemelukwe ${ }^{\mathrm{a} \dagger}$, Brahim Benyahia ${ }^{\mathrm{a}}$, Nuno M. Reis ${ }^{\mathrm{a}}$, Zoltan K. Nagy ${ }^{\mathrm{a}, \mathrm{b}}$, Chris. D. Rielly ${ }^{\mathrm{a}, \dagger}$ \\ ${ }^{a}$ EPSRC Centre for Innovative Manufacturing in Continuous Manufacturing and Crystallisation, \\ Department of Chemical Engineering, Loughborough University, Loughborough, Leicestershire LE11 \\ $3 T U, U K$ \\ ${ }^{\mathrm{b}}$ School of Chemical Engineering, Purdue University, West Lafayette, IN 47907, USA \\ Email: i.i.onyemelukwe@lboro.ac.uk; c.d.rielly@lboro.ac.uk
}

\begin{abstract}
The heat transfer performance of a $5 \mathrm{~mm}$ internal diameter (I.D.) mesoscale continuous oscillatory flow crystalliser with smooth periodic constrictions (herein called SPC meso-tube) is herein reported for the first time for both steady flow and unsteady oscillatory flow conditions. Experimental values of the tube-side Nusselt number, $N u_{t}$, accompanied by an estimability analysis, emphasized the key role played by smooth constrictions and bulk flow velocity in controlling tube-side heat transfer in the SPC meso-tube, while revealing a weaker influence of oscillatory flow on heat transfer enhancement in the tube. Although the presence of smooth constrictions provided an increased surface area to volume (SAV) ratio, and recirculation zones which promoted heat transfer rates, a maximum 1.7-fold heat transfer augmentation was obtained when fluid oscillations were combined with smooth constrictions. The behaviour of the SPC meso-tube was such that increasing the net flow Reynolds number, $R e_{n}$, from 11 up to 54 with the combination of smooth constrictions and oscillatory flow resulted in the attainment of higher rates of heat transfer up to a maximum $N u_{t}$ of 3.09. The Strouhal number, $S t$, was also found to have a more significant effect on the heat transfer performance than oscillatory frequency, $f$. An empirical correlation was for the first time developed to describe the heat transfer characteristics of the SPC meso-tube, and predict $N u_{t}$
\end{abstract}


based on experimental data for the range of net flow and oscillatory flow conditions investigated. A parameter estimability approach was also implemented to enhance the prediction capability of the correlation. The approach was based on a sequential orthogonalisation, thanks to which the most influential factors affecting the tube-side heat transfer were identified given the available experimental data. Overall, the results accentuate the efficient heat transfer capabilities of the SPC meso-tube in low laminar flow regimes, and its suitability for performing cooling crystallisations where tight temperature control of supersaturation is essential.

Keywords: mesoscale, oscillatory flow, heat transfer, smooth periodic constrictions, empirical correlation, flow crystallization

\section{Introduction}

Oscillatory flow mixing has existed for many years as a method of achieving efficient and controlled mixing in various process operations (Van Dijck, 1934; Karr, 1959; Bellhouse et al., 1973; Sobey, 1980; Stephanoff et al., 1980). Recently, within the pharmaceutical industry, there have been significant drives to accelerate more widespread adoption of continuous processing, due to its many potential advantages over traditional batch processes such as lower costs, and reduced environmental footprint (Benyahia et al. 2012; Mascia et al. 2013; Zhao et al., 2014). Their ability to achieve plug flow residence time distributions, scale up much more easily than stirred tank reactors, and provide efficient mixing and particle suspension characteristics has made oscillatory baffled reactors (OBRs) an attractive state-of-the-art technology for converting existing batch crystallisation processes to continuous mode; a specific purpose for which they are known as continuous oscillatory baffled crystallisers (COBCs). In their basic form, conventional scale (typically $>10 \mathrm{~mm}$ I.D.) OBRs are tubular 
devices containing periodically spaced "sharp-edged" orifices or constrictions (SEPC) with oscillatory flow superimposed on a net flow (Dickens et al., 1989; Stonestreet and Van der Veeken, 1999; Harvey et al., 2001; Ni et al., 2002; Harvey et al., 2003a). The scaled-down, mesoscale (typically $4.4-5.0 \mathrm{~mm}$ I.D.) oscillatory flow reactors (meso-OFRs) pioneered by Reis et al. (2005) offer attractive advantages of reduced material inventory and consumption, and the achievement of near plug flow at very low net flow rates (low Reynolds numbers in the laminar regime) (Phan et al., 2011). As such, they are well suited for developing lab-scale continuous crystallisation processes as continuous oscillatory flow crystallisers (mesoscale crystallisers), with minimal use of process materials, or for continuous manufacturing of $\mathrm{kg}$ per-day of added-value chemicals such as crystallisation of APIs.

Mixing and heat transfer are critical process parameters (CPP) for cooling crystallisation, as they control the spatial distribution of supersaturation which impacts on various properties of the crystal product obtained (Zhao et al., 2014). Efficient mixing required for controlling local crystallisation kinetics is readily achieved in COBCs by superimposing an oscillatory flow component which provides vigorous eddy mixing inside each baffle or constriction cavity (Mackley et al., 1990). The heat transfer on the other hand is dependent on the fluid mixing conditions inside the tube and is promoted by chaotic flow that results in a high degree of radial mixing. COBCs can achieve superior heat transfer properties for crystallisation than stirred tank reactors due to their higher surface area to volume (SAV) ratios (Zhao et al., 2014). The SAV is a ratio of the outside area of the tube to the volume within the tube and represents the amount of surface area per unit volume of fluid inside the tube. Three well-known studies of a conventional sharp-edged OBR (Mackley et al., 1990; Mackley and Stonestreet, 1995; Stephens and Mackley, 2002) have confirmed that significant heat transfer enhancement is obtained when both flow oscillation and baffles are present. Mackley and Stonestreet (1995) examined the heat transfer performance of a $12 \mathrm{~mm}$ I.D. sharp-edged OBR with baffle inserts, 
in a $1 \mathrm{~m}$ long stainless-steel shell-and-tube heat exchanger configuration. A 5-fold increase in $N u_{t}$ was observed when only baffles were inserted in the tube, and a 30 -fold increase was achieved when oscillations were superimposed.

Overall, the heat transfer characteristics of conventional SEPC OBRs are well established and predicted by the Mackley and Stonestreet (1995) correlation. For meso-OFRs, which have a variation of baffle configurations (Reis et al., 2005; Phan and Harvey, 2010), their heat transfer characteristics have not been properly investigated, and are still largely speculative (McDonough, 2015). When compared to conventional-sized tubes, the much higher SAV provided by meso-tubes favours enhanced heat transfer for better controlled crystallisation of APIs. So far, no heat transfer investigations have been reported for any of the different geometric designs of mesoscale OFRs, although simulations carried out for nonoscillatory flow in a helical coil meso-tube by Solano et al. (2012) revealed that helical coils, when inserted into a plain meso-tube, would yield a 1.1-fold heat transfer augmentation. Furthermore, the authors showed that an increase in oscillatory Reynolds number, $R e_{o}$ from 10 to 320 caused a 4 -fold increase in the mean $N u_{t}$. Although simulation results for the helical coil meso-tube correspond to general heat transfer behaviour in conventional SEPC OBRs, experimental validations of these predictions are yet to be presented.

The aim of this study is to provide an insight into the heat transfer characteristics of the SPC meso-tube, whereby findings may be applicable to other meso-tubes of similar SPC design (Ejim et al., 2017). The SPC meso-tube is well-suited for bioengineering and pharmaceutical applications due to its smooth constrictions that greatly reduce high shear regions and crystal attrition (Reis et al., 2005), provide superior solids suspension at low flow rates (Reis et al., 2004; Phan et al., 2011), and facilitate gas bubble removal from the meso-tube; hence it is a very important design for crystallisation processes. 


\section{Theory}

\subsection{Oscillatory flow}

The fluid mechanics in the SPC meso-tube can be characterised by three dimensionless groups, these are well described elsewhere (Fitch and Ni, 2003; Reis et al., 2005). At low $R e_{n}$, where laminar flow occurs, the introduction of a small oscillatory flow in a baffled or constricted tube provides 2D axi-symmetrical flow where eddy propagation significantly improves radial mixing and plug flow is attainable (Mackley and Ni, 1991; McDonough et al., 2015). At high values of $R e_{o}$, the mixing becomes very intense, and flow becomes nonaxisymmetric and approaches complete mixed flow conditions (McDonough et al., 2015). For cases where $S t$ is very low (high amplitudes), excessive eddy generation causes vortex propagation into adjacent baffle cavities and the quality of radial mixing decreases (Phan and Harvey, 2012). When $S t=\infty$, the absence of eddy generation to effectively mix the baffle cavity results in flows that are dominated by viscosity and density effects, with high axial dispersion along the length of the tube (Mackley and Ni, 1991).

\subsection{SPC meso-tube}

The SPC meso-tube has an internal diameter, $D$ of ca. $5.0 \mathrm{~mm}$ and a constriction diameter, $d_{o}$, of ca. $2.0 \mathrm{~mm}$ (Figure 1) which gives an open cross-sectional area, $S$, of $16 \%$. The mean spacing between smooth constrictions, $L$, is $13 \mathrm{~mm}$, giving a length-to-diameter ratio, $L / D$, of 2.6, which is significantly higher than the ratios of $1.5-2$ for conventional sharp-edged COBCs (Brown and Ni, 2012; Callaghan and Ni, 2012; Zhao et al., 2014). The geometry of the SPC meso-tube differs drastically from the sharp-edged baffled tube for which Mackley and Stonestreet (1995) derived a general $N u_{t}$ correlation. The contrasting baffle type and scale of these tubes are chiefly responsible for limiting applicability of the Mackley-Stonestreet 
correlation to the SPC meso-tube. The sharp-edged baffled tube investigated by the authors had a $D$ of $12.0 \mathrm{~mm}$, a $d_{0}$ of $7 \mathrm{~mm}(S=0.34)$, and an $L / D$ of 1.5 .

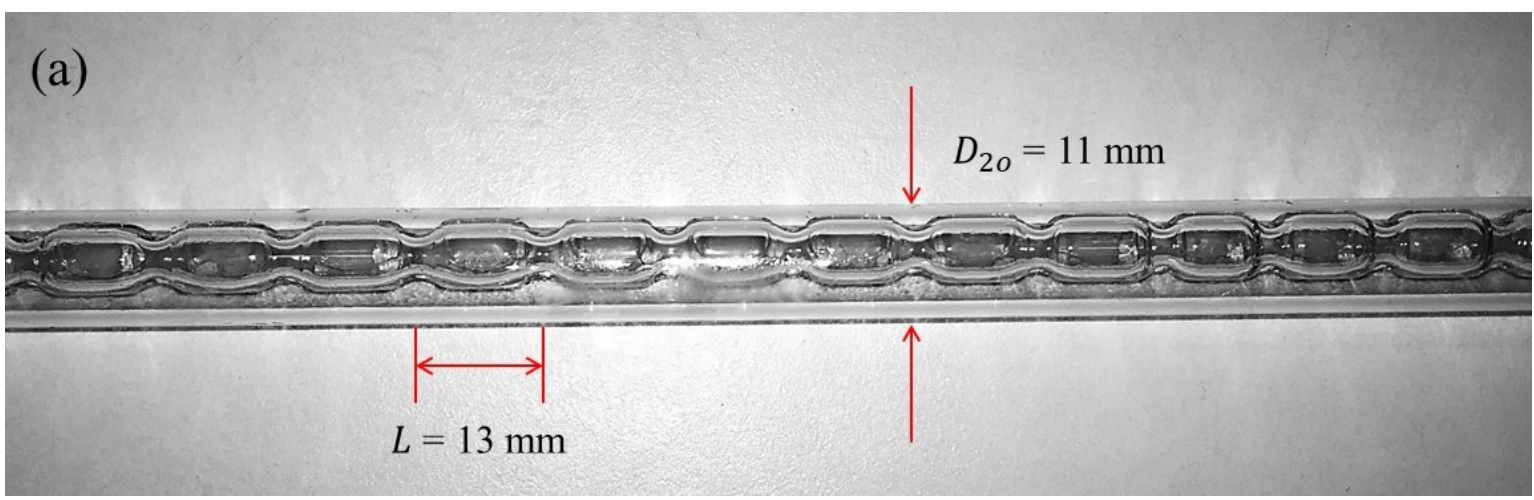

(b)

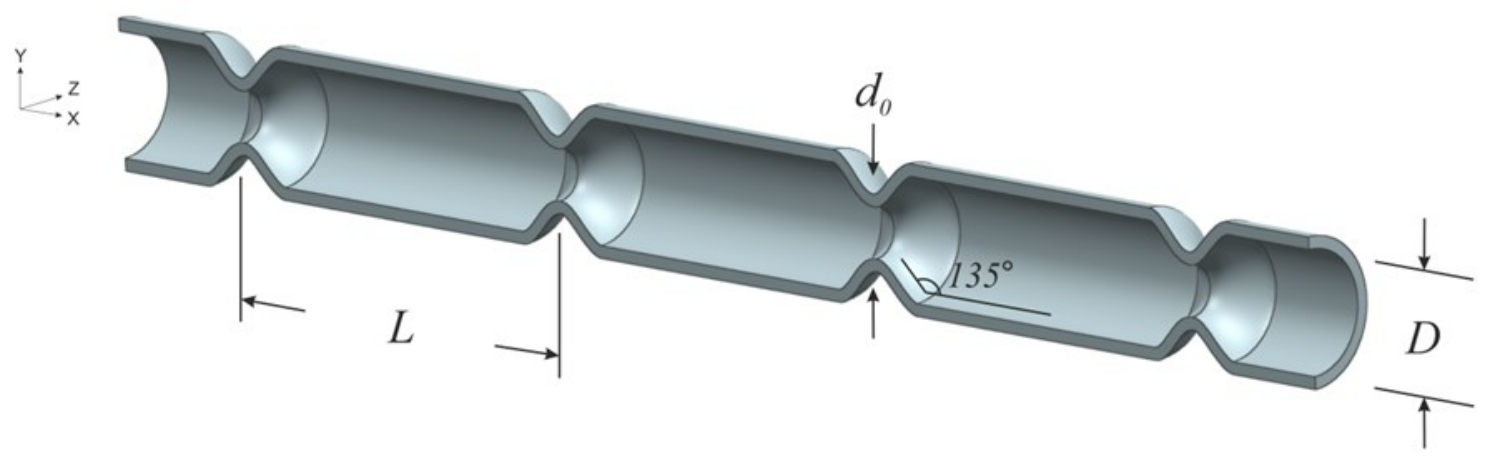

Figure 1 (a) Section of jacketed SPC meso-tube and (b) Internal CFD visualisation of the SPC mesotube with labelled dimensions.

A tube of its scale requires much stronger oscillations than the SPC meso-tube to provide efficient mixing and near-plug-flow behaviour. The Mackley-Stonestreet correlation was derived from experiments in the range $R e_{n}=100-1200$ and $R e_{o}=300-800$, an operating range deemed as impractical for the SPC meso-tube, since most of its advantages for crystallisation would be lost. When applied to predict steady non-oscillatory flow heat transfer performance in the SPC meso-tube for the range $R e_{n}=11-54$, the Mackley-Stonestreet correlation was found to significantly under-predict $N u_{t}$ values by an average of $58 \%$ (see Figure 4). For unsteady oscillatory flow heat transfer in the range $R e_{o}=39-197$, the 
correlation under-predicted $N u_{t}$ by as much as $65 \%$ at the lowest $R e_{o}$, and over-predicted $N u_{t}$ by as much as $1974 \%$ at the highest $R e_{o}$. This suggested the SPC meso-tube displayed a different relationship to that described by the Mackley-Stonestreet correlation.

\subsection{Tube-side Nusselt number determination}

The Nusselt number describes the magnitude of convective heat transfer occurring parallel to the surface normal of the boundary layer, and perpendicular to the mean fluid flow within a tube. In other words, it is the ratio of convective heat transfer to conductive heat transfer. Heat transfer performance can be determined by evaluating the dimensionless $N u_{t}$ as follows:

$$
N u_{t}=\frac{h_{t} D_{1 i}}{k}
$$

where $D_{1 i}$ is the inside diameter of the largest part of the cell (m), $k$ is the thermal conductivity of the process fluid ( $\left.\mathrm{W} \mathrm{m}^{-1} \mathrm{~K}^{-1}\right)$, and $h_{t}$ is the tube-side heat transfer coefficient $\left(\mathrm{W} \mathrm{m}^{-2} \mathrm{~K}^{-1}\right)$.

Note that $D_{1 i}$ is herein taken as the mean tube diameter, $D_{1 i m}=2 \sqrt{\frac{V}{\pi L_{1}}}$, where $L_{1}$ is the active tube length $(\mathrm{m})$, and $V$ is the measured volume in the active tube length $\left(\mathrm{m}^{3}\right)$. The mean tube diameter was used in calculations for $R e_{n}, R e_{o}, S t$, and mean velocity $u_{m} . N u_{t}$ can be determined from measured overall heat transfer coefficient (referred to the outside area of the inner tube), given by the following equation (Stephens and Mackley, 2002):

$$
\frac{1}{U_{21}}=\frac{1}{h_{t}}+\frac{D_{1 i} \ln \left(D_{1 o} / D_{1 i}\right)}{2 k_{g}}+\frac{D_{1 i}}{D_{1 o} h_{a}}
$$


where $k_{g}$ is the thermal conductivity for the inner tube wall material (glass) (W m $\left.{ }^{-1} \mathrm{~K}^{-1}\right), D_{1 o}$ is the outer diameter of the inner tube (m), $h_{a}$ is the heat transfer coefficient in the annulus (W $\left.\mathrm{m}^{-2} \mathrm{~K}^{-1}\right)$, and $U_{21}$ is the overall heat transfer coefficient $\left(\mathrm{W} \mathrm{m}^{-2} \mathrm{~K}^{-1}\right)$ between the cooling and process fluids. $U_{21}$ is related to heat flux as follows:

$$
Q_{1}=A U_{21} \Delta T_{l m}=\dot{m}_{1} C_{p 1} \Delta T_{1}
$$

where $\Delta T_{l m}$ is the log mean temperature difference (LMTD) of the heat exchanger, $\Delta T_{1}$ is the temperature difference of the process fluid over the length of the heat exchanger, $\dot{m}_{1}$ is the mass flow rate of the process fluid, and $A$ is the outside heat transfer area of the inner tube. The LMTD is calculated using:

$$
\Delta T_{l m}=\frac{\Delta T_{2}-\Delta T_{1}}{\ln \left[\Delta T_{2} / \Delta T_{1}\right]}=\frac{\left(T_{1 \text { out }}-T_{2 \text { in }}\right)-\left(T_{1 \text { in }}-T_{2 \text { out }}\right)}{\ln \left[\left(T_{1 \text { out }}-T_{2 \text { in }}\right) /\left(T_{1 \text { in }}-T_{2 \text { out }}\right)\right]}
$$

where $T_{1 \text { in }}, T_{1 \text { out }}$ are the process fluid inlet and outlet temperatures, and $T_{2 \text { in }}, T_{2 \text { out }}$ are the cooling fluid inlet and outlet temperatures respectively. The high flow rate maintained in the annulus provides a much larger heat capacity rate and heat transfer coefficient than that of the process fluid, enabling the cooling fluid to absorb a large quantity of heat with negligible change in its temperature along the tube. This results in a special case where the temperature of the cooling fluid remains approximately constant throughout the heat exchanger length, and $T_{2 \text { in }}=T_{2 o u t}=T_{w}$. Substituting into Equation (3) gives an equation for $U_{21}$ :

$$
U_{21}=\frac{\dot{m}_{1} C_{p 1} \Delta T_{1}}{A} \frac{\ln \left[\left(T_{1 o u t}-T_{2 i n}\right) /\left(T_{1 \text { in }}-T_{2 o u t}\right)\right]}{\Delta T_{1}+\Delta T_{2}}
$$


$U_{21}$ is obtained from experimental data and $N u_{t}$ is calculated using Equation (6) (Mackley and Stonestreet, 1995):

$$
\frac{1}{N u_{t}}=\frac{k_{1}}{D_{1 i}}\left[\frac{1}{U_{21}}-\frac{D_{1 i}}{D_{1 o} h_{a}}-\frac{D_{1 i} \ln \left(\frac{D_{1 o}}{D_{1 i}}\right)}{2 \kappa_{g}}\right]
$$

\section{Experimental methods}

\subsection{Experimental apparatus}

An SPC mesoscale crystalliser was modified for heat transfer experiments to determine $N u_{t}$ in the SPC meso-tube. The setup consisted of 2 identical jacketed SPC meso-tubes connected as concentric tube heat exchangers by an unjacketed U-bend and operated in counter-current mode (see Figure 2). The thickness of the glass wall was ca. $1 \mathrm{~mm}$ and $L_{1}$ was $0.657 \mathrm{~m}$. The process and annulus fluid chosen was deionized water with temperaturedependent thermal properties. The annulus fluid was pumped at a constant flow rate of $\sim 61$

$\min ^{-1}$, and the process fluid was pumped continuously by a Labhut Series 1500 Dual Piston Pump from a de-gassed reservoir. A constant temperature, $T_{w}$, was maintained in the annulus by a Huber Ministat 230 temperature control bath. Table 1 summarises the specifications of the heat exchanger. 


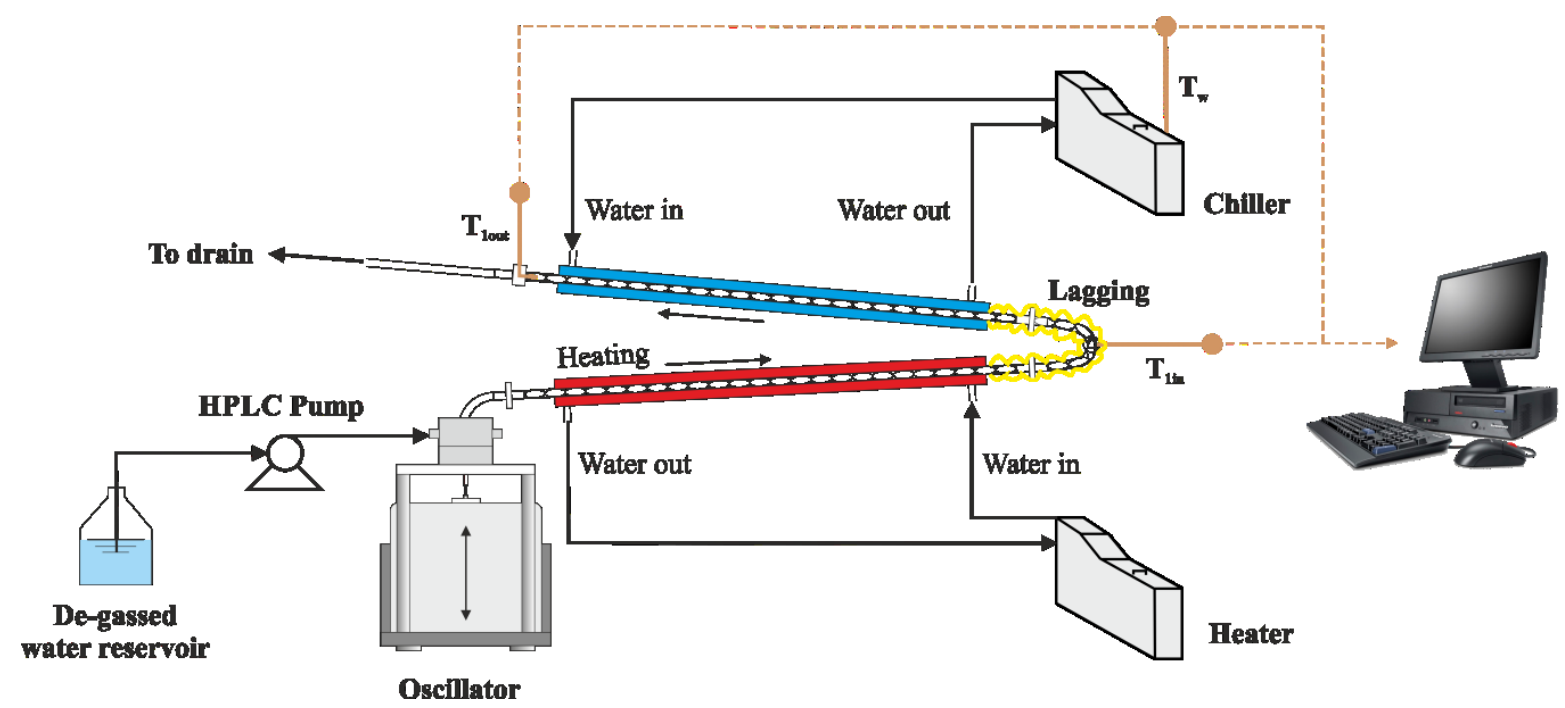

Figure 2 Schematic representation of the heat transfer apparatus.

Fluid oscillations were achieved by a piston-driven diaphragm connected with an electromagnetic oscillator (LDS, UK, V406). A signal generator (LDS, UK, PO100) was used to adjust the frequency of oscillation, $f(\mathrm{~Hz})$, and an amplifier (LDS, UK, PA100E) controlled the centre-to-peak amplitude of oscillation, $x_{0}(\mathrm{~mm})$. Manipulating $x_{0}$ and $f$ controlled the intensity of mixing applied in the tube, otherwise known as the oscillatory Reynold's number, $R e_{o}$ (Reis et al., 2005). The resultant time-dependent displacement was measured by a calibrated displacement transducer attached to the piston yoke.

Table 1 Heat exchanger specifications

\begin{tabular}{ll}
\hline Specifications & \\
\hline Tube outside diameter, $D_{1 o}(\mathrm{~mm})$ & 7.0 \\
Tube internal diameter, $D_{1 i}(\mathrm{~mm})$ & 5.0 \\
Jacket external diameter, $D_{2 o}(\mathrm{~mm})$ & 11.0 \\
Jacket internal diameter, $D_{2 i}(\mathrm{~mm})$ & 9.0 \\
Active tube length, $L_{1}(\mathrm{~mm})$ & 657 \\
Total heat transfer area, $A\left(\mathrm{~m}^{2}\right)$ & 0.011 \\
Heat transfer area per unit length, $A_{L 1},\left(\mathrm{~m}^{2} \mathrm{~m}^{-1}\right)$ & 0.02 \\
Hydraulic diameter, $D_{h}=D_{2 i}-D_{1 o}\left(\mathrm{~mm}^{2}\right.$ & 2.0 \\
Material of construction & $\mathrm{Glass}$ \\
Wall thermal conductivity, $k_{g}\left(\mathrm{~W} \mathrm{~m} \mathrm{~m}^{-1} \mathrm{~K}^{-1}\right)$ & 1.1 \\
\hline
\end{tabular}


$T_{1 \text { in }}, T_{1 \text { out }}$, and $T_{w}$ were measured using $3 \mathrm{~K}$-type thermocouples with mineral insulated sensors (Thermosense) inserted into the U-bend, tube exit, and the temperature control bath respectively. The entire section connecting the heat exchangers was sufficiently lagged such that heat loss to the surrounding was negligible and the temperature measured at the U-bend could be taken as the inlet temperature $T_{1_{\text {in }}}$. Each thermocouple was calibrated for linearity before installation. The thermocouples were connected to a computer via an Advantech USB4718 data acquisition module.

\subsection{Heat transfer experiment}

At the start of the experiment, deionized water was pumped at a steady net flow rate into section 1 where it was heated up to a desired inlet temperature, $T_{1_{\text {in }}}$ of $55^{\circ} \mathrm{C}$. The resulting hot water was then cooled to a final temperature, $T_{1_{\text {out }}}$ measured at the exit of the heat exchanger. The annulus of the heat exchanger was maintained at a constant temperature, $T_{w}$ of $\sim 3.5^{\circ} \mathrm{C}$ by a constant turbulent flow of water $\left(3.9 \mathrm{~m} \mathrm{~s}^{-1}\right)$ with a much greater heat capacity rate $\left(C_{1}=416\right.$ $\left.\mathrm{J} \mathrm{K}^{-1} \mathrm{~s}^{-1}\right)$ than that of the process fluid $\left(C_{2}=0.14-0.8 \mathrm{~J} \mathrm{~K}^{-1} \mathrm{~s}^{-1}\right)$. The Nusselt number in the annulus was estimated using the Dittus Boelter turbulent flow expression (Equation (7)). The heat transfer coefficient $h_{a}$, was estimated at $13,041 \mathrm{~W} \mathrm{~m}^{-2} \mathrm{~K}^{-1}$ and assumed constant for all experiments conducted. At such high values, minor changes in the heat transfer coefficient were found to have very little effect on the tube side Nusselt number calculated. The resistance from the glass wall was found to be $0.164 \mathrm{~m} \mathrm{~K} \mathrm{~W}^{-1}$.

$$
N u_{a}=0.023 R e_{n}^{0.8} \operatorname{Pr}^{0.3}
$$


A set of non-oscillatory experiments were first conducted in a plain meso-tube, and then in the SPC meso-tube. The oscillatory $x_{0}$ and $f$ were varied for different unsteady flow experiments subsequently carried out in the SPC meso-tube. For every oscillatory and net flow condition, the mean $N u_{t}$ was calculated from recorded data corresponding to steady-state operation i.e. when temperature values had become steady. Experiments were performed in the

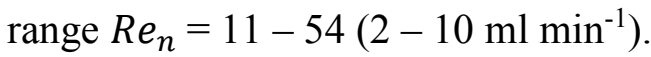

Table 2 shows the physical properties of the cooling and process fluids based on the mean bulk temperature $\left(\frac{T_{\text {in }}+T_{\text {out }}}{2}\right)$ in the active length of the heat exchanger.

Table 2 Temperature-dependent thermophysical properties of cooling and process fluids (Perry et al., 1999)

\begin{tabular}{lll}
\hline Physical properties & Process fluid at $32.5^{\circ} \mathrm{C}$ & Cooling fluid at $3.5^{\circ} \mathrm{C}$ \\
\hline Density, $\rho\left(\mathrm{kg} \mathrm{m}^{-3}\right)$ & 992.80 & 1005 \\
Viscosity, $\mu(\mathrm{Pa} \mathrm{s})$ & $7.87 \times 10^{-4}$ & $1.5 \times 10^{-3}$ \\
Thermal conductivity, $k\left(\mathrm{~W} \mathrm{~m}^{-1} \mathrm{~K}^{-1}\right)$ & 0.614 & 0.579 \\
Specific heat capacity, $C_{p}\left(\mathrm{~J} \mathrm{Kg}^{-1} \mathrm{~K}^{-1}\right)$ & 4188 & 4185 \\
Prandlt number, $P r$ & 5.37 & 10.67 \\
\hline
\end{tabular}

\subsection{Heat transfer model based on concentric tube heat exchanger}

Figure 3 shows a cross-section of the jacketed SPC meso-tube as a concentric tube heat exchanger, in which heat is exchanged across the boundary between a process fluid contained within an inner tube, and cooling fluid contained in the annulus. The process and cooling fluids flow counter-currently to each other with mass flow rates $\dot{m}_{1}$ and $\dot{m}_{2}\left(\mathrm{~kg} \mathrm{~s}^{-1}\right)$ respectively. $T_{1}(x)$ and $T_{2}(x)$ are the temperatures at a distance $x$ in the inner tube and annulus respectively. $T_{1_{\text {in }}}$ and $T_{1_{\text {out }}}$ are the entry and exit temperatures of the process fluid, while $T_{2_{\text {in }}}$ and $T_{2_{\text {out }}}$ are the entry and exit temperatures of the cooling fluid in the annulus. 


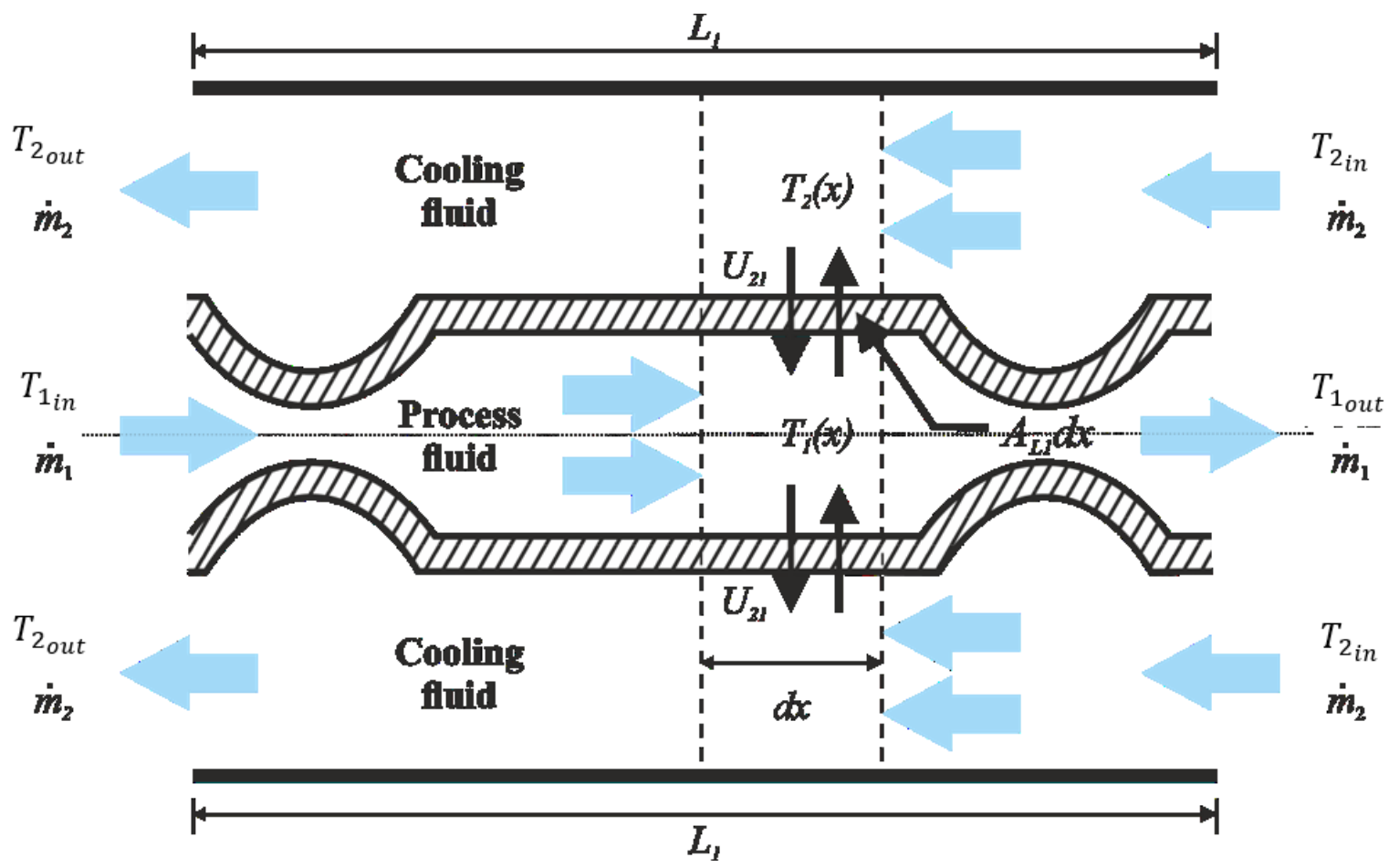

Figure 3 Heat transfer process occurring between process and cooling fluids.

Taking a differential length, $d x$, of this concentric tube heat exchanger, an energy balance can be carried out for the process and cooling fluids that yields Equations $(8-9)$ respectively.

$$
\begin{aligned}
& \dot{m}_{1} C_{p 1} \frac{d T_{1}}{d x}=A_{L 1} U_{21}\left(T_{2}-T_{1}\right) \\
& \dot{m_{2}} C_{p 2} \frac{d T_{2}}{d x}=-A_{L 1} U_{21}\left(T_{1}-T_{2}\right)
\end{aligned}
$$

where $C_{p 1}$ and $C_{p 2}$ are the specific heat capacities $\left(\mathrm{J} \mathrm{kg}^{-1} \mathrm{~K}^{-1}\right)$ of the process and cooling fluids respectively, and $A_{L 1}$ is the outside heat transfer area per unit axial length of the inner tube $\left(\mathrm{m}^{2}\right.$ $\left.\mathrm{m}^{-1}\right)$

From Figure 3 above, 


$$
\begin{aligned}
& T_{1}=\left(T_{1}\right)_{\text {in }} \text { at } x=0 \\
& T_{2}=\left(T_{2}\right)_{\text {in }} \text { at } x=L_{1}
\end{aligned}
$$

Equations $(8-9)$ are ordinary differential equations (ODEs) that can be solved analytically subject to the initial and boundary conditions in Equations $(10-11)$ respectively to give Equations $(12-13)$.

$$
\begin{aligned}
& T_{1}=-C+\left(T_{1}\right)_{i n}+C \exp (D x) \\
& \left(T_{2}\right)_{i n}=\left(T_{1}\right)_{i n}+C\left(\left(X_{1} D+1\right) \exp \left(D L_{1}\right)-1\right)
\end{aligned}
$$

where $C$ is an integration constant, $D=-\frac{\left(X_{1}+X_{21}\right)}{X_{1} X_{21}}, X_{1}=\frac{\dot{m_{1}} C_{p 1}}{A_{L 1} U_{21}}$, and $X_{21}=\frac{\dot{m_{1}} C_{p 1}}{A_{L 1} U_{21}}$.

\section{Results and discussion}

\subsection{Heat transfer at steady flow conditions}

Heat transfer experiments were performed in a plain meso-tube and the SPC meso-tube to evaluate the effect of smooth periodic constrictions on the heat transfer performance for the case of steady non-oscillatory flow conditions. Both tubes had an internal diameter of $5 \mathrm{~mm}$. Figure 4 shows the tube-side Nusselt number as a function of $R e_{n}$ for steady non-oscillatory flow. For the plain meso-tube, an increase in $N u_{t}$ was observed as $R e_{n}$ increased, confirming 
a contribution to heat transfer that is expected from an increase in forced convection within the tube.

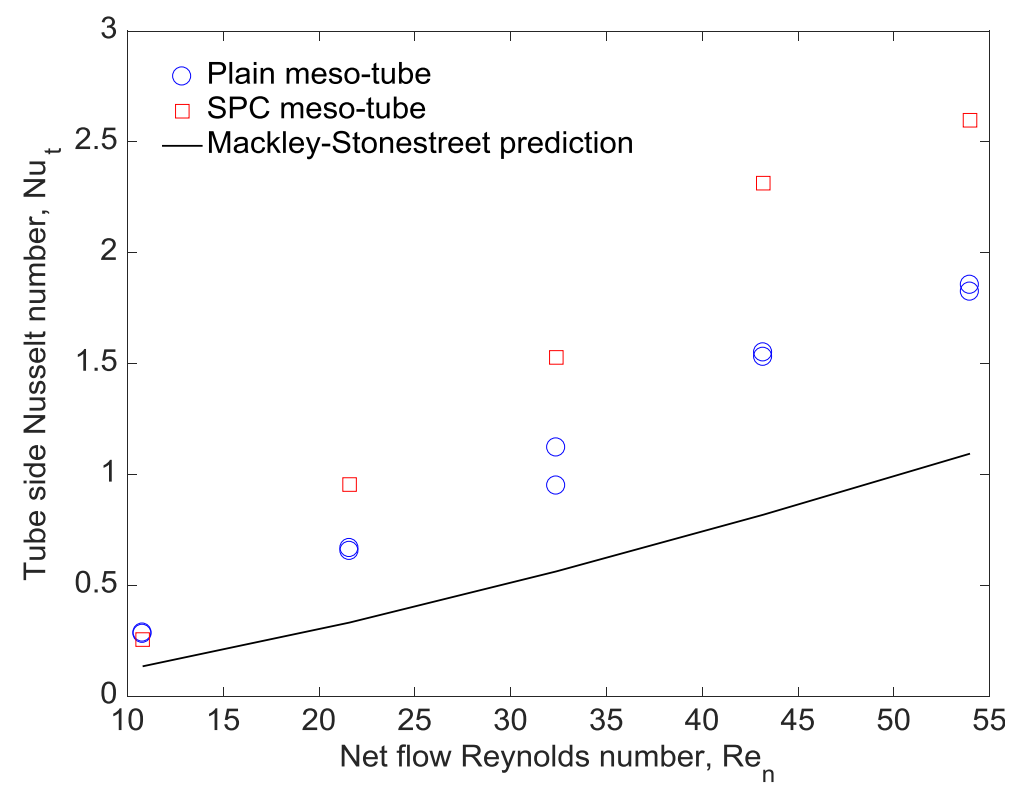

Figure 4 Comparison of $N u_{t}$ obtained for a plain meso-tube and the SPC meso-tube for steady flow. $R e_{n}=10.79-53.97$.

Comparisons could not be made between $N u_{t}$ values for the plain meso-tube and standard literature correlations for laminar flow in circular smooth-walled tubes. For instance, the experimental range of applicability of the empirical Sieder-Tate correlation for smooth tubes (Sieder and Tate, 1936) does not extend to such low $R e_{n}$ ranges for which $N u_{t}$ values were determined in the plain meso-tube. Hausen's correlation (Hausen, 1959) for a broad range of Graetz numbers, $G r=\left(\operatorname{Re} e_{n} \operatorname{Pr} \frac{D}{L}\right)$, was equally not applicable since fully developed flow had not been achieved in the plain meso-tube, a condition for which $N u_{t} \approx 3.66$.

For the SPC meso-tube, a stronger increase in $N u_{t}$ was obtained with increasing $R e_{n}$; this is not only attributed to the increased SAV from the presence of smooth constrictions in the tube, but also to a level of secondary mixing resulting from the formation of recirculation zones between the constrictions, as reported by Reis et al. (2005). Smooth constrictions restrict 
fluid flow and promote eddy formation; consequently, fluid velocities are increased at regions around the constrictions thus enhancing the heat transfer coefficient. The maximum $N u_{t}$ achieved in the plain meso-tube for non-oscillatory flow was 10 times lower than the value obtained by Mackley and Stonestreet (1995) for a $12 \mathrm{~mm}$ I.D. plain tube, due to the lower range of $R e_{n}$ that could be achieved practically. $N u_{t}$ values for this range of $R e_{n}(10.79-53.97)$ agree well with literature data for steady flow in circular pipes (Incropera and DeWitt, 2011). The maximum $N u_{t}$ obtained for steady non-oscillatory flow in the SPC meso-tube was 2.60 at $R e_{n}=53.97$, which is 1.4-fold improvement over the $N u_{t}$ obtained in the plain meso-tube for the same value of $R e_{n}$. At the lowest $R e_{n}$ investigated, the value for $N u_{t}$ obtained in the SPC meso-tube was 0.26 , a $10 \%$ improvement to the heat transfer in the plain meso-tube. Although the SPC meso-tube had a smaller overall heat transfer area $\left(A_{S P C}=0.011 \mathrm{~m}^{2}\right)$ compared to the plain meso-tube $\left(A_{\text {plain }}=0.014 \mathrm{~m}^{2}\right)$, the resulting SAV was higher at $1190 \mathrm{~m}^{-1}$ compared to $1138 \mathrm{~m}^{-1}$ for the plain meso-tube. The significant heat transfer enhancement arising from a higher SAV and presence of smooth constrictions in the SPC meso-tube is in general agreement with behaviour observed in the conventional sharp-edged baffled tube by Mackley and Stonestreet (1995). Simulation results obtained by Solano et al. (2012) for similar nonoscillatory conditions $\left(R e_{n}=10, \operatorname{Re} e_{o}=0, \operatorname{Pr}=5.5\right)$ in a $5 \mathrm{~mm}$ I.D. meso-tube, showed a heat transfer augmentation of 1.1 when a helical coil inserts were included.

\subsection{Heat transfer at unsteady, oscillatory flow conditions}

A second set of experiments was performed to investigate what effect an unsteady oscillatory flow would have on the heat transfer performance of the SPC meso-tube relative to steady non-oscillatory flow. For each $R e_{n}, f$ was varied from $0-10 \mathrm{~Hz}$ to give a range of $R e_{o}$ at a fixed $S t$ of $0.8\left(x_{0}=0.5 \mathrm{~mm}\right)$. Figure 5 shows the heat transfer obtained in the SPC meso- 
tube for increasing values of $R e_{o}$ at $R e_{n}=10.79$. The introduction of a small oscillatory element $\left(R e_{o}=39\right)$ caused a $22 \%$ improvement in heat transfer performance $\left(N u_{t}=0.337\right)$ from the case with no oscillation $\left(N u_{t}=0.276\right)$. A maximum $31 \%$ improvement was obtained at $R e_{o}=118$, after which $N u_{t}$ plateaued off, and no further heat transfer enhancement was detected in the system from measured steady-state data.

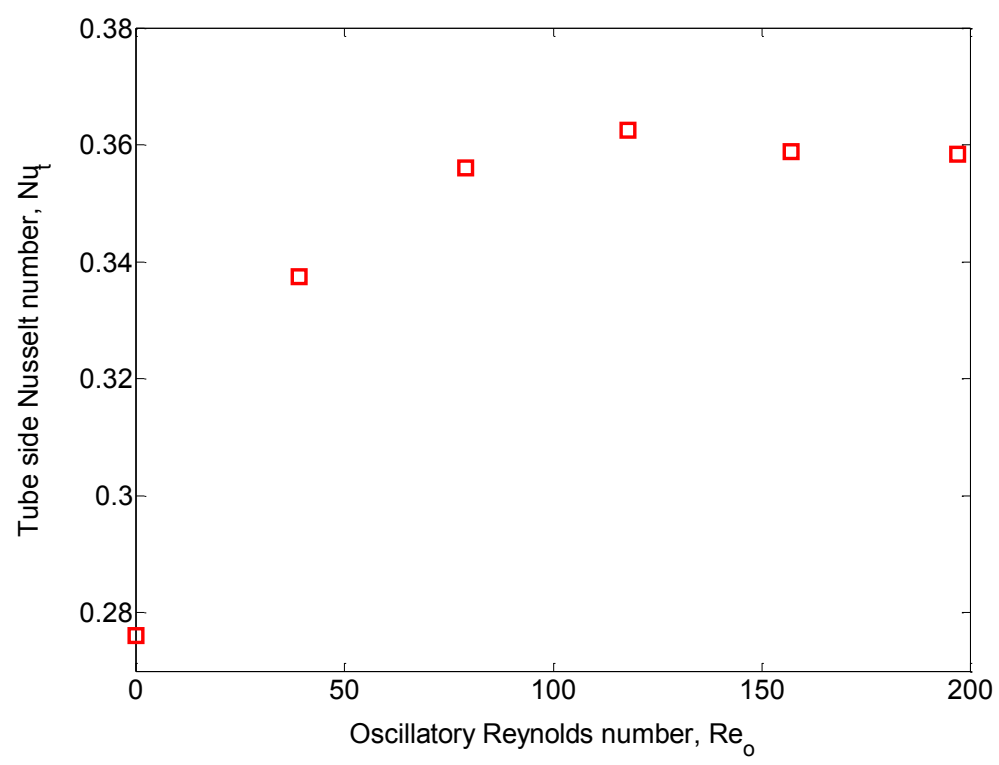

Figure $5 N u_{t}$ as a function of $R e_{o} \cdot R e_{n}=10.79, S t=0.8$.

Subsequent fixed net flow experiments reproduced this limited effect of oscillation on heat transfer performance. A stacked plot of these experiments in Figure 6 highlights a weaker sensitivity of $N u_{t}$ to $R e_{o}$, and shows that changing $R e_{n}$ has a stronger effect on heat transfer performance than changing $R e_{o}$. Higher values of $N u_{t}$ were obtained at higher $R e_{n}$, again highlighting the steady flow contribution to higher rates of heat transfer. Figure 6 and Figure 7 signify that adding an oscillatory component onto a steady net flow contributes an inappreciable difference to heat transfer performance in the SPC meso-tube. Table 3 demonstrates the diminishing effect of oscillations that is exhibited when net flow is increased. 


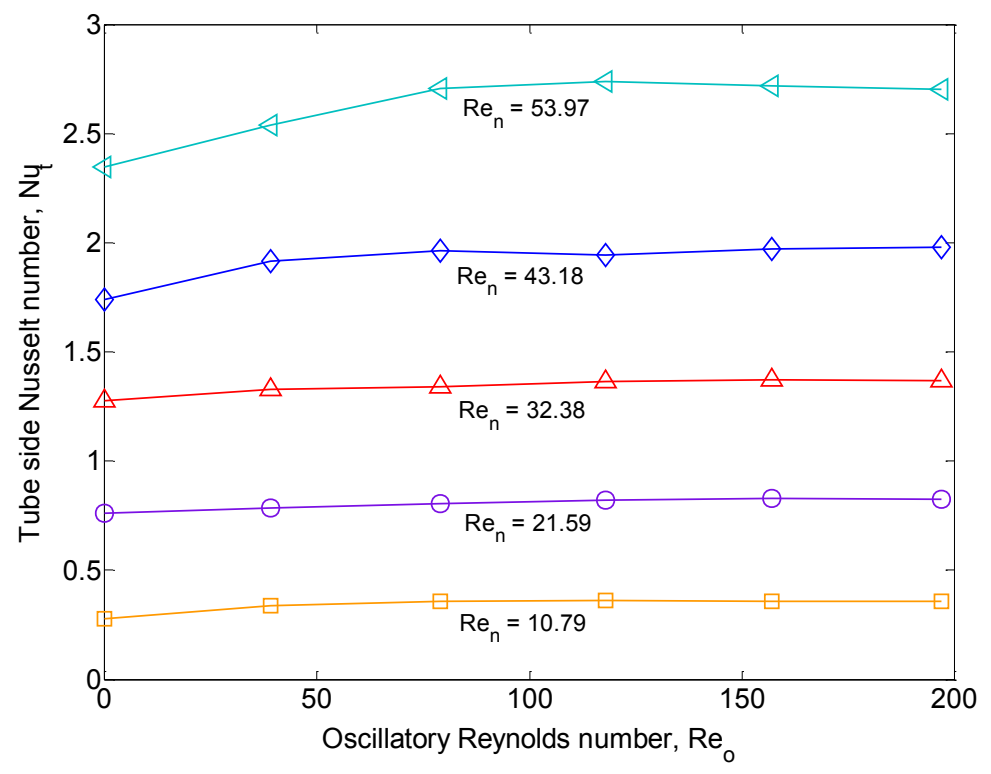

Figure $6 N u_{t}$ as a function of $R e_{o} . f=0-10 \mathrm{~Hz}, R e_{n}=10.79-53.97, S t=0.8$.

Table $3 \%$ improvement in $N u_{t}$ versus non-oscillatory case

\begin{tabular}{|c|c|c|c|c|c|c|c|c|c|c|}
\hline \multirow[t]{2}{*}{$R e_{n}$} & \multicolumn{2}{|c|}{$R e_{o}=39$} & \multicolumn{2}{|c|}{$R e_{o}=79$} & \multicolumn{2}{|c|}{$R e_{o}=118$} & \multicolumn{2}{|c|}{$R e_{o}=157$} & \multicolumn{2}{|c|}{$R e_{o}=197$} \\
\hline & $\varphi$ & $\%$ imp & $\varphi$ & $\%$ imp & $\varphi$ & $\%$ imp & $\varphi$ & $\%$ imp & $\varphi$ & $\%$ imp \\
\hline 10.79 & 3.6 & 22.2 & 7.3 & 29.0 & 10.9 & 31.3 & 14.6 & 29.9 & 18.3 & 29.8 \\
\hline 21.59 & 1.8 & 2.9 & 3.7 & 5.6 & 5.5 & 7.7 & 7.3 & 8.5 & 9.1 & 8.2 \\
\hline 32.38 & 1.2 & 4.0 & 2.4 & 4.9 & 3.6 & 6.7 & 4.8 & 7.4 & 6.1 & 7.1 \\
\hline 43.18 & 0.9 & 10.2 & 1.8 & 12.8 & 2.7 & 11.7 & 3.6 & 13.3 & 4.6 & 13.7 \\
\hline 53.97 & 0.7 & 8.2 & 1.5 & 15.3 & 2.2 & 16.8 & 2.9 & 15.8 & 3.7 & 15.2 \\
\hline
\end{tabular}

Velocity ratio, $\varphi=R e_{o} / R e_{n}$.

On inspecting Table 3, three observations are made:

i. For each set of $R e_{o}$ the greatest \% improvement to heat transfer occurred at the lowest $\operatorname{Re}_{n}$ (highest $\varphi$ ). Interestingly, the $\%$ improvement dropped off drastically for lower values of $\varphi$.

ii. For almost all sets of $R e_{n}$, the maximum \% improvement appeared to be attained between $R e_{o}=118-157$.

iii. It could be argued for all sets of $R e_{n}$ that beyond $R e_{o}$ of $39(f=2 \mathrm{~Hz})$, the $\%$ improvement obtained with respect to oscillatory velocity is insignificant (see 
Figure 6), indicating no further room for heat transfer enhancement in the SPC meso-tube.

The maximum $N u_{t}$ obtained was of the order 2.74 at $R e_{o}=118$, which was a 1.2-fold increase over the non-oscillatory result at the same $R e_{n}$ of 53.97. The effect of oscillation $f$ on the heat transfer performance in the SPC meso-tube contrasts sharply from what has been observed in the sharp-edged baffled tube. Experimental results by Mackley and Stonestreet (1995) for the baffled tube showed that varying $f$ has a strong effect on heat transfer, and that $N u_{t}$ increases almost linearly with $R e_{o}$. On the other hand, variations in $S t$ had only a small effect on the heat transfer performance. This dissimilarity can be attributed to the difference in scale of both tubes. The smaller-diameter SPC meso-tube has a greater surface area-to-volume ratio $\left(\mathrm{SAV}=1190 \mathrm{~m}^{-1}\right)$ than the baffled tube $\left(\mathrm{SAV} \approx 389 \mathrm{~m}^{-1}\right)$. As the hot process fluid enters the SPC meso-tube, the abundant heat transfer surface area facilitates rapid heat transfer across the wall to the annulus fluid and a depletion of temperature driving force occurs exponentially along the tube. The introduction of an oscillatory element contributes to $h_{t}$, leading to faster temperature decay in a shorter distance. The plateauing of $N u_{t}$ observed in the SPC meso-tube can be explained as the absence of driving force for further heat transfer due to the process fluid temperature closely approaching the wall temperature at the tube outlet. In view of this, a significantly shorter SPC meso-tube would be required to obtain any significant heat transfer augmentation from oscillatory flow. Due to practical limitations, it was not possible to capture temperature readings at intermediate points along the SPC meso-tube.

Figure 7 reveals the dependency of oscillatory flow heat transfer enhancement on the steady flow component. The greatest $\%$ improvement from the steady flow component was obtained by doubling $R e_{n}$ from 10.79 to 21.59 . This corresponded to the greatest decline in $\%$ improvement from the oscillatory flow component. As net flow was increased, the \% 
improvement to $N u_{t}$ from the steady flow component quickly passed through a maximum and subsequently plateaued owing to further depletion of temperature driving force at higher $R e_{n}$ in the SPC meso-tube.

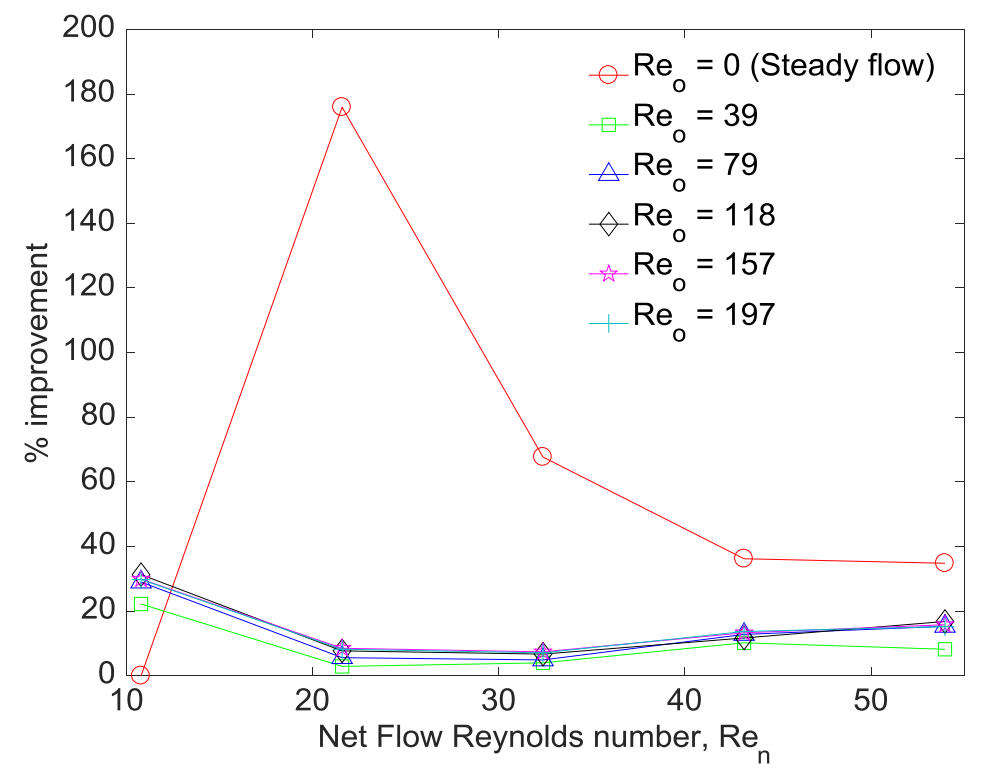

Figure $7 \%$ improvement in $N u_{t}$ as a function of $R e_{n}$.

The dependency observed is such that a stronger steady flow contribution to heat transfer is accompanied by a weaker oscillatory flow contribution and vice versa, as dictated by the overall driving force available. Also, since the overall driving force becomes increasingly limited as $R e_{n}$ is increased, the heat transfer enhancement due to oscillatory flow is effectively damped at higher $R e_{n}$.

The effect of $S t$ on the heat transfer performance was also studied by varying $x_{0}$. Figure 8 shows $N u_{t}$ as a function of the maximum oscillatory velocity, $2 \pi f x_{0}\left(\mathrm{~m} \mathrm{~s}^{-1}\right)$. For this scale, it is evident that the heat transfer performance has a limited dependence on oscillatory velocity, and is impaired by lower $S t$. 


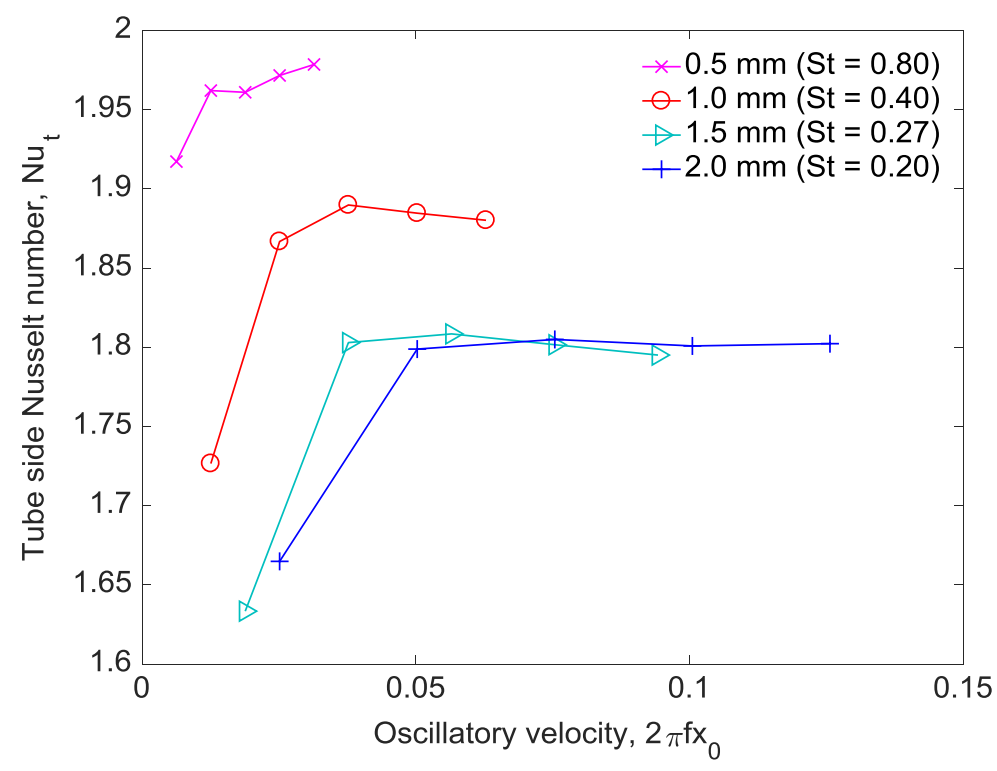

Figure 8 Tube-side heat transfer as a function of $2 \pi f x_{0}$ for oscillatory flow. $R e_{n}=43.18 . f=2-10$ $\mathrm{Hz}, \mathrm{St}=0.2-0.8$.

Each set of $x_{0}$ exhibited an initial sharp increase in $N u_{t}$, followed by a plateauing beyond $f=$ $6 \mathrm{~Hz}$. Unsurprisingly, the maximum $N u_{t}$ was obtained at $S t$ of 0.8 , which coincides with the optimal St identified in previous work for good plug flow mixing in the SPC meso-tube. For such small magnitudes of $N u_{t}$, the Strouhal number can be said to have a significant effect on heat transfer in the SPC meso-tube.

\subsection{Empirical correlation for the tube-side Nusselt number}

\subsubsection{Identification of parameters and experimental fitting}

Figure 9 describes the relationship between the tube-side heat transfer, steady flow, and unsteady oscillatory flow in the SPC meso-tube. $R e_{n}$ was varied from $11-54$ and the sets of $R e_{o}=39,79,118,157,197$ on the plot correspond to $f=2,4,6,8,10 \mathrm{~Hz}$ respectively. Overall, in the SPC meso-tube higher rates of heat transfer were achieved at higher $\operatorname{Re}_{n}$ values by superimposing an oscillatory element on steady net flow. At higher $R e_{n}$, the oscillatory curves diverge from the steady flow curve. This is in stark contrast to the relationship observed in the 
conventional sharp-edged baffled tube, where at larger values of $R e_{n}$, the best-fitted oscillatory curves tend asymptotically towards the best-fitted steady flow curves (Mackley and Stonestreet, 1995).

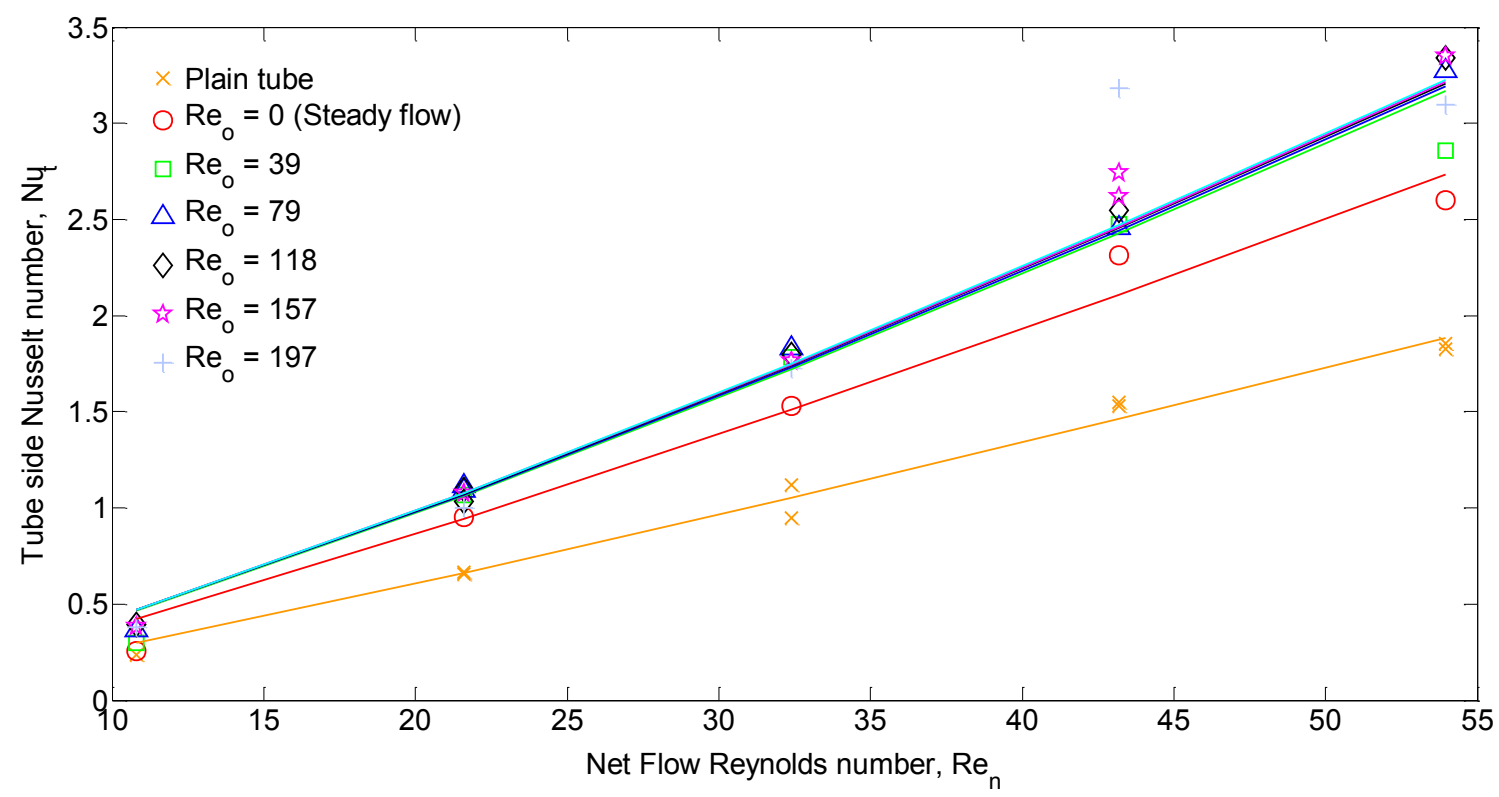

Figure 9 Experimental and best-fitted tube-side Nusselt number as a function of both $R e_{o}$ and $R e_{n}$ for the SPC meso-tube.

An empirical correlation was developed to describe the dependency of $N u_{t}$ on the steady flow and oscillatory flow in the SPC meso-tube. Equation (14) shows the structure of this correlation with a total of 7 parameters that were considered and represented as $a, b, c, \alpha, \beta, \gamma, \theta$.

$$
N u_{t}=a \operatorname{Re}_{n}{ }^{\alpha} \operatorname{Pr}^{\beta}+b\left[\operatorname{Re}_{o}{ }^{\gamma} \operatorname{Re}_{n}{ }^{\theta} \frac{s t}{c}\right]
$$

The identification of the complete set of 7 parameters, without distinction, using the experimental data available, can lead to poor parameter estimates that degrade the prediction capability of the correlation. This is commonly due to the correlation between parameters or their effects within the selected experimental space, and/or the weak effect of some parameters 
on the output prediction, in this case $N u_{t}$. To address this issue, it was necessary to determine the optimal subset of parameters and their estimates that capture effectively the experimental data and maximise the prediction capability of the correlation. One of the effective ways to achieve this objective was to implement an estimability analysis (also called practical identifiability) (Yao et al., 2003; Benyahia et al., 2013).

\subsubsection{Estimability analysis}

Prior to the final parameter identification step, it was necessary to determine the subset of parameters with the strongest influence on the measured output based on available data, as well as the correlation between the parameter effects using the method of estimability or practical identifiability analysis. The result of an estimability analysis is usually a number of parameters that are sufficient to represent the information provided by the experimental data. Usually, the non-estimable parameters are set to nominal values, or the entire correlation is redefined to remove these parameters (Yao et al., 2003). Accurate estimation of the model parameters is required to obtain reliable predictions of $N u_{t}$, and consequently the heat transfer performance of the SPC meso-tube.

The development of an effective solution to the parameter selection problem required the quantification of the influence of each parameter on the measured outputs. This approach indicates which parameters are the most important and most likely to affect predictions of the correlation. The first step of the method is the evaluation of the sensitivity coefficients:

$$
S_{i j}=\frac{\partial \hat{y}_{i}}{\partial \hat{p}_{j}}, j=1,2, \ldots n_{p}
$$


where $n_{p}$ is the number of parameters. Because of the different orders of magnitude of the various parameters in the correlation, it is necessary to normalize the sensitivity coefficients with respect to the nominal values of the parameters and their corresponding output predicted by the correlation. This will allow for a reliable comparison between the effects of different parameters on the predications of the correlation.

$$
\left.S_{i j}\right|_{t=t_{k}}=\left.\frac{\bar{p}_{j}}{\left.\bar{y}_{i}\right|_{t=t_{k}}} \frac{\partial \hat{y}_{i}}{\partial \hat{p}_{j}}\right|_{t=t_{k}}
$$

where $\bar{p}_{j}$ is the nominal value of the $j$ th parameter and $\left.\bar{y}_{i}\right|_{t=t_{k}}$ is the correlation prediction of the $i$ th output evaluated at a sampling time $t_{k}$ using the nominal vector of the parameters $(\overline{\boldsymbol{p}})$.

The overall sensitivities of the different outputs with respect to the full set of parameters was summarised in a matrix of sensitivity coefficients $(\boldsymbol{Z})$. Each column of this matrix evaluates the global effect of a given parameter on the process outputs at different measurement times, whereas each row represents the effect of the full set of parameters on a given output at a fixed time of measurement.

$$
\boldsymbol{Z}=\left[\begin{array}{ccc}
\left.S_{11}\right|_{t=t_{1}} & \cdots & \left.S_{1 n_{p}}\right|_{t=t_{1}} \\
\vdots & \ddots & \vdots \\
\left.S_{n_{y} 1}\right|_{t=t_{1}} & \cdots & \left.S_{n_{y} n_{p}}\right|_{t=t_{1}} \\
\left.S_{11}\right|_{t=t_{2}} & \cdots & \left.S_{1 n_{p}}\right|_{t=t_{2}} \\
\vdots & \ddots & \vdots \\
\left.S_{n_{y} 1}\right|_{t=t_{n_{m}}} & \cdots & \left.S_{n_{y} n_{p}}\right|_{t=t_{n_{m}}}
\end{array}\right]
$$

After the selection of the nominal values of the parameters from preliminary parameter estimation (Table 4) the sensitivity matrix was computed numerically in MATLAB ${ }^{\circledR} 2016$, 
based on a sequential orthogonalisation algorithm (Benyahia, 2010). The resulting correlation for the tube-side Nusselt number is shown in Equation (18):

$$
N u_{t}=0.01616 R e_{n}{ }^{1.16} \operatorname{Pr}^{0.3}+0.0016\left[\operatorname{Re}_{o}{ }^{0.08} \operatorname{Re}_{n}{ }^{1.42} \frac{S t}{1.136}\right]
$$

The first term of the correlation represents the steady flow contribution to heat transfer, while the second term is the augmentation provided when an oscillatory component is superimposed on steady net flow. Note the inclusion of the dimensionless Strouhal number in the oscillatory term, as this was found to have a separate effect from $R e_{o}$ on $N u_{t}$. Much of the contribution to heat transfer comes from the steady net flow, as is indicated by the higher coefficient of the first term. The steady flow term is an analogue of the Dittus Boelter turbulent flow equation, as is the first term of the Mackley-Stonestreet correlation in Equation (19). The exponent of $R e_{n}$ accounts for the presence of smooth periodic constrictions; this value is lower than that of the Mackley-Stonestreet correlation and represents the less chaotic conditions created by smooth constrictions and steady flow in this range of $R e_{n}$ investigated.

$$
N u_{t}=0.0035 \operatorname{Re}_{n}^{1.3} \operatorname{Pr}^{0.3}+0.3\left[\frac{R e_{o}^{2.2}}{\left(R e_{n}+800\right)^{1.25}}\right]
$$

The oscillatory term in the correlation suggests that the effect of oscillation is multiplied by the steady flow, and that oscillations by themselves have a negligible effect. Thus, for a fixed $R e_{o}$, higher values of $N u_{t}$ are achieved by increasing $R e_{n}$. The opposite is observed in the Mackley-Stonestreet correlation, where for $R e_{o} \gg R e_{n}$, the effect of oscillation is superimposed on steady behaviour. The effect of $S t$ is captured by the relationship with its 
coefficient; such that for smaller St, the heat transfer contribution from the oscillatory term diminishes regardless of $R e_{o}$, and values of $N u_{t}$ fall closer to those for steady non-oscillatory flow in the SPC meso-tube. In the absence of oscillations, Equation (18) simplifies to the first term only and corresponds to the best-fitted curve for steady flow in Figure 9. It is important to state that this correlation was derived for an SPC meso-tube with an active length of $0.65 \mathrm{~m}$ and fitted for measured $N u_{t}$ values within the experimental range of $R e_{n}$ and $R e_{o}$ defined earlier.

Table 4 Nominal values of the correlation parameters

\begin{tabular}{ll}
\hline Parameter & Value \\
\hline$a$ & 0.01616 \\
$b$ & 0.0016 \\
$c$ & 1.136 \\
$\alpha$ & 1.16 \\
$\beta$ & 0.3 \\
$\gamma$ & 0.08 \\
$\theta$ & 1.42 \\
\hline
\end{tabular}

On implementing the orthogonalisation algorithm, the parameters were ranked according to their estimability potential. The most estimable parameters present the highest effect (the column of the matrix $\mathrm{Z}$ with the highest magnitude or Euclidean norm) and lowest pairwise correlation coefficients. Cut-off values were identified to help determine the set of parameters that capture more reliably, the information contained in the experimental data and consequently, maximise the prediction capability of the correlation. Depending on the selected cut-off value, different parameter sets could be obtained. Table 5 shows that the parameter with the highest estimability potential in the correlation is $\alpha$, which is the exponent of $R e_{n}$ in the steady term. The second parameter is $\theta$, corresponding to the $R e_{n}$ exponent in the oscillatory term; and the third most estimable parameter is $a$, the coefficient of $R e_{n}$ in the steady term. 
Table 5 Subsets of the most estimable parameters obtained for different cut-off values

\begin{tabular}{lllllllll}
\hline Cut-off value, $\lambda$ & $\mathbb{P}$ & & & & & & \\
\hline 15.4 & $\alpha$ & & & & & & & \\
1.83 & $\alpha$ & $\theta$ & & & & & & \\
0.02 & $\alpha$ & $\theta$ & $a$ & & & & & \\
$4 \times 10^{-3}$ & $\alpha$ & $\theta$ & $a$ & $b$ & & & & \\
$17 \times 10^{-4}$ & $\alpha$ & $\theta$ & $a$ & $b$ & $c$ & & & \\
$9 \times 10^{-17}$ & $\alpha$ & $\theta$ & $a$ & $b$ & $c$ & $\gamma$ & & \\
$4.2 \times 10^{-18}$ & $\alpha$ & $\theta$ & $a$ & $b$ & $c$ & $\gamma$ & $\beta$ \\
\hline
\end{tabular}

The selection of $\alpha$ as the strongest parameter emphasises the paramount importance of the smooth constrictions to the heat transfer characteristics of the SPC meso-tube as demonstrated by Figure 4 .

Table 6 Ranking of the parameters with the highest estimability potential

\begin{tabular}{ll}
\hline Parameter & Rank \\
\hline$\alpha$ & 1 \\
$\theta$ & 2 \\
$a$ & 3 \\
$b$ & 4 \\
$c$ & 5 \\
$\gamma$ & 6 \\
$\beta$ & 7 \\
\hline
\end{tabular}

Aside Table 4, the effect of the cut-off value on the optimal number of required parameters is depicted in Figure 10. This indicates that three parameters would be sufficient to explain the heat transfer behaviour in the SPC meso-tube, given a cut-off value of $1 \%$, as suggested in the literature (Yao et al. 2003; Benyahia et al. 2013). To further refine and maximise the outcomes of the estimability method, we need to quantify the effect of the number of parameters to be identified, or the size of the optimal set of the most estimable parameters, on the model prediction performance compared to the experimental data. This effect is depicted in Figure 11 as the optimal value of the maximum likelihood criterion versus set size of the most estimable parameters, starting from one parameter (i.e. the most estimable parameter $\alpha$ ). Again, Figure 11 shows that 3 parameters provide a sufficient set to build a reliable correlation for the tube- 
side Nusselt number. However, a further improvement of the agreement between the predictions and experimental measurements was obtained by selecting more parameters. A satisfactory trade-off between a minimum number of parameters and high accuracy of the prediction was finally met with 6 parameters selected among the 7 correlation parameters.

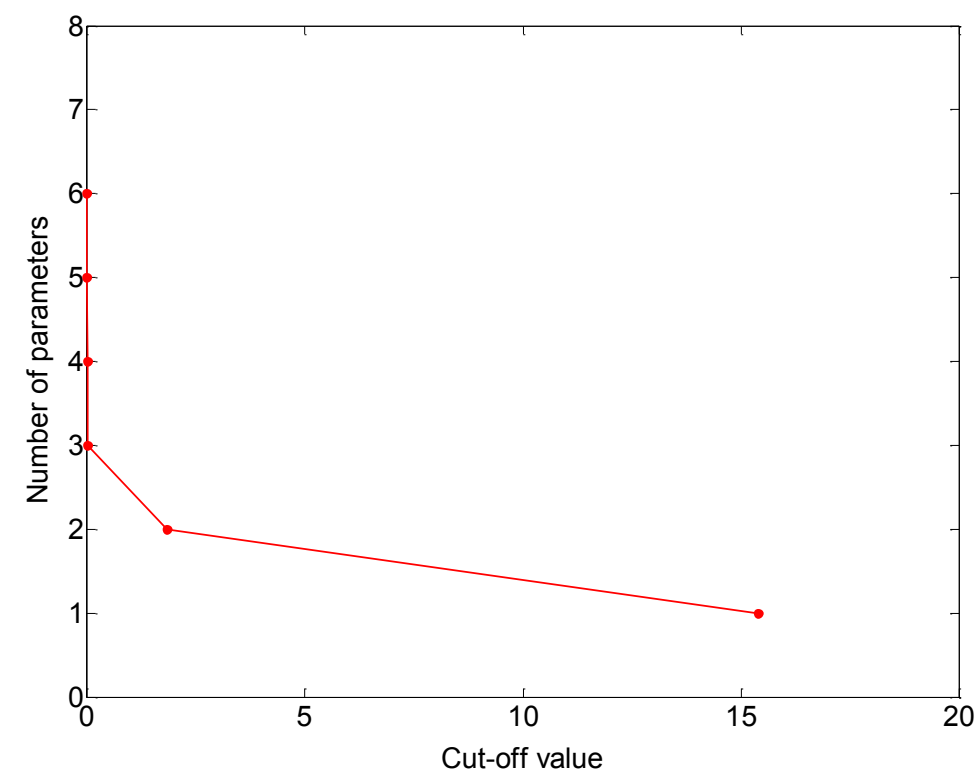

Figure 10 Number of selected parameters vs. cut-off value in tube-side Nusselt number correlation.

The selection of $\gamma$ as the sixth parameter once again highlights the weak influence of oscillations on heat transfer augmentation in the SPC meso-tube. The selection of $c$ as the fifth parameter points out that $S t$ plays a more significant role than oscillation $f$. $\theta$, an exponent of $R e_{n}$ in the oscillatory term, was ranked as the second strongest parameter; this affirms that the total contribution from the oscillatory term is largely provided by the net flow component. This also agrees with experimental findings that varying $R e_{n}$ has a stronger effect on heat transfer than varying $f$. Overall, from the ranking of parameters, it is now clear that the control of heat transfer in the SPC meso-tube is dictated by the smooth constrictions and net flow velocity. 
The 6 parameter estimates in Figure 11 were obtained by minimizing the maximum likelihood criterion (Walter and Pronzato, 1994), which in this case is the sum of square differences between the experimental measurements and the correlation predictions. The relationship between the sum of square differences (SSE) and the number of parameters was similar to that found in Figure 10.

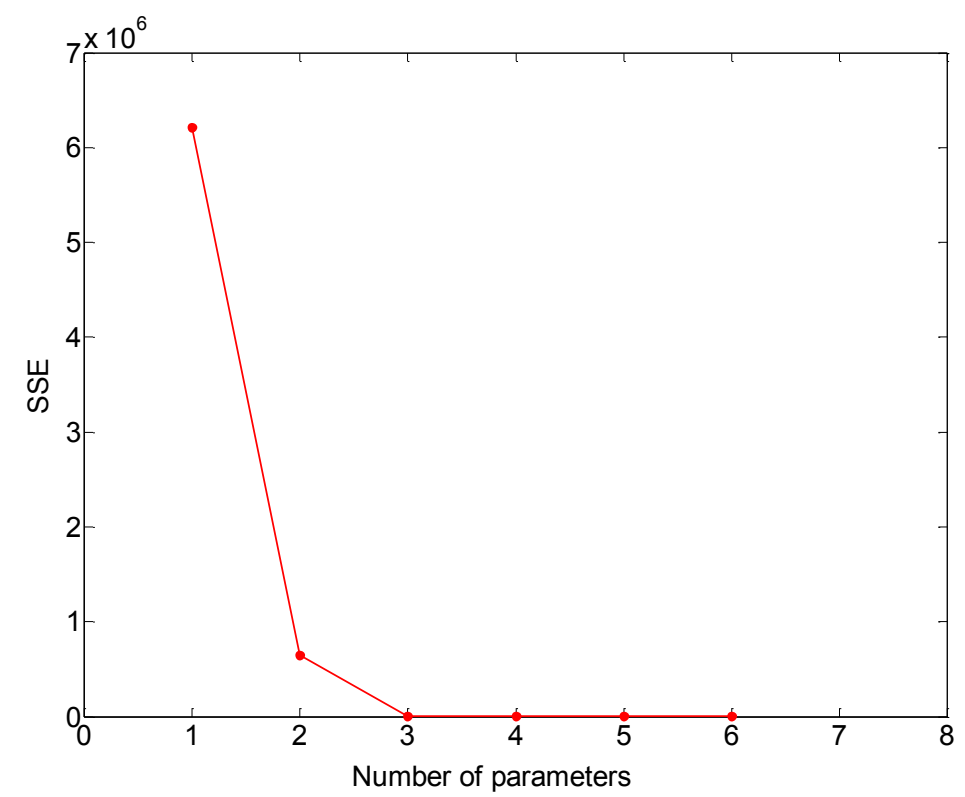

Figure 11 Effect of minimizing the maximum likelihood criterion on the number of parameters.

The parameter $\beta$, which corresponds to the exponent of the Prandlt number, $\operatorname{Pr}$, was found to have an infinitesimal effect on $N u_{t}$, and as a result was not selected in the final subset of estimable parameters. $\beta$ was kept fixed at its nominal value, and the dependence of $N u_{t}$ on $\operatorname{Pr}$ was not investigated. This means that the correlation may be re-parameterized to exclude $\beta$, without compromising on the accuracy of predictions of $N u_{t}$. 


\section{Conclusions}

Experimental investigations into the heat transfer characteristics of the SPC meso-tube showed that smooth constrictions within the SPC meso-tube significantly enhance the tubeside heat transfer, a behaviour consistent with general observations in conventional SEPC OBRs. An estimability analysis revealed the strong dependency of heat transfer rate on the smooth constrictions and bulk (net) flow velocity, rather than oscillatory flow as established in SEPC OBRs. For the active length of SPC meso-tube investigated, it was found that oscillations provided a limited heat transfer augmentation, however oscillatory flow is expected to provide further heat transfer enhancement in tubes of much shorter active lengths or higher diameterto-length ratio $\left(D / L_{1}>0.0076\right)$. For the experimental conditions investigated, heat transfer rate was found to be weakly dependent on the oscillatory velocity; instead, having a strong dependency on the steady net flow. The heat transfer rate was found to show more sensitivity to the Strouhal number than oscillation frequency, with the SPC meso-tube showing poorer heat transfer performance for $S t<0.8$; a contrasting behaviour to that observed by Mackley and Stonestreet (1995) for the sharp-edged baffled tube.

The data presented in this work highlights the similarities and differences of the heat transfer characteristics in SPC meso-tubes and SEPC OBRs. A correlation to describe the heat transfer behaviour of the SPC meso-tube was fitted to experimental data for a range of $R e_{n}=$ $10.79-53.97$ and $R e_{o}=0-197$, and a systematic and rigorous approach based on parameter estimability was used to enhance the prediction capability the correlation. The relationship described by the correlation suggests that the effect of oscillation is multiplied by the steady flow, and that oscillations by themselves have a negligible effect. The opposite is observed in the Mackley-Stonestreet correlation, where for $R e_{o} \gg R e_{n}$, the effect of oscillation is superimposed on steady behaviour. 
While the new correlation can reliably predict the tube-side Nusselt number within this range of experimental conditions, its veracity is dependent on the baffle type present in the tube, in this case smooth periodic constrictions. Its predictions will also hold true for SPC meso-tubes of similar diameter-to-length ratio.

\section{Acknowledgements}

The authors would like to thank Mr. Emmanuel Kimuli for providing CFD visualisations of the SPC meso-tube.

\section{Funding}

This work was supported by the EPSRC (EP/I033459/1) Centre for Innovative Manufacturing in Continuous Manufacturing and Crystallisation (CMAC) and the Doctoral Training Centre in Continuous Manufacturing and Crystallisation (EP/K503289/1).

Declarations of interest: None

\section{References}

Bellhouse, B., Bellhouse, F., Curl, C., Macmillan, T., Gunning, A., Spratt, E., MacMurray, S., Nelems, J., 1973. A high efficiency membrane oxygenator and pulsatile pumping system, and its application to animal trials. Trans. Am. Soc. Artif. Inter. Organs 19, $72-79$.

Benyahia, B., 2010. Modélisation, expérimentation et optimisation multicritère d'un procédé de copolymérisation en émulsion en présence d'un agent de transfert de chaîne. Ph.D. Thesis, National Polytechnic Institute of Lorraine, Nancy-University, France.

Benyahia, B, Lakerveld, R, Barton, P.I., 2012. A plant-wide dynamic model of a continuous pharmaceutical process, Ind. Eng. Chem. Res., 51(47), pp.15393-15412, ISSN: 0888-5885.

Benyahia, B., Latifi, M.A., Fonteix, C., Pla, F., 2013. Emulsion copolymerization of styrene and butyl acrylate in the presence of a chain transfer agent. Part 2: Parameters estimability and confidence regions. Chem. Eng. Sci $90,110-118$.

Callahan, C.J., Ni, X., 2012. Probing into nucleation mechanisms of cooling crystallisation of sodium chlorate in a stirred tank crystalliser and an oscillatory baffled crystalliser. Cryst. Growth. Des. 12, 2525 - 2532. 
Dickens, A., Mackley, M., Williams, H., 1989. Experimental residence time distribution measurements for unsteady flow in baffled tubes. Chem. Eng. Sci. 44, $1471-1479$.

Ejim, L. N., Yerdelen, S., McGlone, T., Onyemelukwe, I., Johnston, B., Florence, A. J., Reis, N. M., 2017. A factorial approach to understanding the effect of inner geometry of baffled mesoscale tubes on solids suspension and axial dispersion in continuous, oscillatory liquid-solid plug-flows. Chem. Eng. J., 308, 669 682.

Fitch, A.W., Ni, X., 2003. On the determination of axial dispersion coefficient in a batch oscillatory baffled column using laser induced fluorescence. Chem. Eng. J., 92, 243 - 253.

Harvey, A., Mackley, M., Stonestreet, P., 2001. Operation and optimization of an oscillatory flow continuous reactor. Ind. Eng. Chem. Res. 40, 5371 - 5377.

Harvey, A., Mackley, M., Reis, N., Teixeira, J., Vicente, A., 2003. The fluid mechanics relating to a novel oscillatory flow micro reactor, in: $4^{\text {th }}$ European Congress of Chemical Engineering, Granada, 0-6.4-004.

Harvey, A., Mackley, M., Seliger, T., 2003. Process intensification of biodiesel production using a continuous oscillatory flow reactor. J Chem Technol Biotechnol 78:338-341.

Hausen, H., 1959. Neue Gleichungen fur die Warmeubeitragung bei freier oder erzwungener stromung. Allg. Waermetech., 9, $75-79$.

Incropera, F.P., DeWitt, D.P., 2011. Fundamentals of heat and mass transfer. $7^{\text {th }}$ edition, London:Wiley.

Karr, A., 1959. Performance of a reciprocating-plate extraction column. AIChE J., 446 - 452.

Mackley, M., Tweddle, G.M., Wyatt, I.D., 1990. Experimental heat transfer measurements for pulsatile flow in baffled tubes. Chem. Eng. Sci. 45, 1237 - 1242.

Mackley, M., Stonestreet, P., 1995. Heat transfer and associated energy dissipation for oscillatory flow in baffled tubes. Chem. Eng. Sci. 50, $2211-2224$.

Mackley, M., Ni, X., 1991. Mixing and dispersion in a baffled tube for steady laminar and pulsatile flow. Chem. Eng. Sci., 46 (12), $3139-3151$.

Mascia, S., Heider, P,L., Zhang, H., Lakerveld, R., Benyahia, B., Barton, P.I., Braatz, R.D., Cooney, C.L., Evans, J.M.B., Jamison, T.F., Jensen, K.F., Myerson, A.S., Trout, B.L., 2013. End-to-End Continuous Manufacturing of Pharmaceuticals: Integrated Synthesis, Purification, and Final Dosage Formation, Angewandte Chemie International Edition, 52 (47), pp.12359-12363, ISSN: 1433-7851

McDonough, J.R., Phan, A.N., Harvey, A.P., 2015. Rapid process development using oscillatory baffled mesoreactors - A state-of-the-art review. Chem. Eng. J. 265, 110 - 121.

Ni, X., Jian, H., Fitch, A., 2002. Computational fluid dynamic modelling of flow patterns in an oscillatory baffled column. Chem. Eng. Sci. 57, 2849 - 2862.

Ni, X., Brown, C., 2012. Evaluating crystal growth of antisolvent crystallisation of paracetamol in an oscillatory baffled crystalliser with video imaging. Paper presented at 2012 Annual Conference of the British Association for Crystal Growth, Glasgow, United Kingdom, 17/06/12 - 20/06/12.

Perry, R.H., 1997. Perry's chemical engineer's handbook. $2^{\text {nd }}$ ed. New York: McGraw Hill.

Phan, A.N., Harvey, A.P., 2010. Development and evaluation of novel designs of continuous mesoscale oscillatory baffled reactors. Chem. Eng. J. 159, $212-219$.

Phan, A., Harvey, A., Rawcliffe, M., 2011. Continuous screening of base-catalysed biodiesel production using new designs of mesoscale oscillatory baffled reactor. Fuel Process. Technol. 92, 1560 - 1567.

Phan, A., Harvey, A., 2012. Characterisation of mesoscale oscillatory helical baffled reactor - experimental approach, Chem. Eng. J. 180, 229 - 236.

Reis, N., Vicente, A.A., Teixeira, J.A., Mackley, M.R., 2004. Residence times and mixing of a novel continuous oscillatory flow screening reactor. Chem. Eng. Sci. 59, 4967 - 4974. 
Reis, N., Harvey, A., Mackley, M., Vicente, A., Teixeira, J., 2005. Fluid mechanics and design aspects of a novel oscillatory flow screening mesoreactor. Trans. IChemE 83, $357-371$.

Sobey, I., 1980. On flow through furrowed channels. Part 1. Calculate flow patterns. J. Fluid Mech. $96,1-26$.

Solano, J.P., Herrero, R., Espín, S., Phan, A.N., Harvey, A.P., 2012. Numerical study of the flow pattern and heat transfer enhancement in oscillatory baffled reactors with helical coil inserts. Chem. Eng. Res. Des. 90, $732-742$.

Sieder, E.N., Tate, G.E., 1936. Heat transfer and pressure drop of liquids in tubes. Ind. Eng. Chem. 28 (12), $1429-1435$.

Stephanoff, K., Sobey, I., Bellhouse, B., 1980. On flow through furrowed channels. Part 2. Observed flow patterns. J. Fluid Mech. 96, 27 - 32.

Stephens, G.G., Mackley, M.R., 2002. Heat transfer performance for batch oscillatory flow mixing. Exp. Therm. Fluid Sci. 25, $583-594$.

Stonestreet, P., Van Der Veeken, P., 1999. The effects of oscillatory flow and bulk flow components on residence time distribution in baffled tube reactors. Trans. IChemE 77, $671-684$.

Van Dijck, W., 1934. Process and apparatus for intimately contacting fluids, US Patent 2,011,186.

Walter, E., Pronzato, L., 1994. Identification of Parametric Models from experimental data. Berlin: Springer.

Yao, K.Z., Shaw, B.M., Kou, B., McAuley, K.B., Bacon, D.W., 2003. Modeling ethylene/butene copolymerization with multi-site catalysts: Parameter estimability and experimental design. Poly. React. Eng. 11, $563-588$.

Zhao, L., Raval, V., Briggs, N.E.B., Bhardwaj, R.M., Mcglone, T., Oswald, I.D.H., Florence, A.J., 2014. From discovery to scale-up: $\alpha$-lipoic acid: nicotinamide co-crystals in a continuous oscillatory baffled crystalliser. CrystEngComm 16, $5769-5780$. 